\title{
IDENTIFIKASI KONSENTRASI NATRIUM KLORIDA (NaCl) PADA JAHE DAN LENGKUAS GILING DIBEBERAPA PASAR TRADISIONAL DI KOTA PADANG
}

\author{
Lisa Yusmita \\ Program Studi Teknologi Industri Pertanian Universitas Dharma Andalas \\ Email: lisayusmita04@yahoo.com
}

\begin{abstract}
ABSTRAK
Penelitian ini bertujuan untuk menentukan kadar garam $(\mathrm{NaCl})$ yang terdapat pada jahe giling dan lengkuas giling yang dijual di beberapa pasar tradisional di kota Padang. Sampel diambil di beberapa tempat di Pasar Tradisional Kota Padang terutama pasar yang dikelola oleh Pemerintah Daerah. Pengambilan sampel menggunakan metode Purposive Sampling dengan mempertimbangkan bahwa jahe giling dan lengkuas giling berasal dari penyalur dan pedagang yang memproduksi sendiri, diambil dari pedagang yang paling ramai dikunjungi dan paling banyak menjual jahe giling dan lengkuas giling. Berdasarkan hasil penelitian, didapatkan kadar Natrium Klorida $(\mathrm{NaCl})$ yang teridentifikasi $<2 \%$ pada seluruh sampel yang diuji.

Kata Kunci-Jahe Giling; Lengkuas Giling; Natrium Klorida; Pasar Tradisional
\end{abstract}

\section{PENDAHULUAN}

Sejak abad ke-16, Indonesia sudah dikenal sebagai negara penghasil rempah-rempah didunia baik berupa umbi akar, rimpang, buah, biji dan sebagainya. Salah satu pemanfaatan rempah-rempah ini adalah untuk keperluan industri pangan khususnya sebagai bumbu masakan yang memberikan warna, rasa dan aroma yang sedap pada makanan. Bumbu masakan didefenisikan sebagai campuran yang terdiri dari atas satu atau beberapa rempah yang ditambahkan pada bahan makanan pada saat pengolahan ataupun penyiapan dengan tujuan untuk meningkatkan rasa, warna dan aroma alami dari makanan sehingga dapat meningkatkan penerimaan konsumen. Penambahan bumbu bertujuan untuk menghasilkan cita rasa tertentu yang diinginkan dalam makanan dan meningkatkan daya awet suatu masakan (Hambali et al, 2005).

Umumnya di pasaran terdapat dua jenis bumbu, yaitu bumbu segar dan bumbu olahan. Bumbu segar merupakan bumbu yang terbuat dari campuran berbagai rempah dalam keadaan segar yang telah dihaluskan, biasanya disebut juga dengan bumbu giling. Sementara bumbu olahan yaitu bumbu yang terbuat dari campuran rempah-rempah yang telah mengalami pengolahan misalnya penumisan (Hambali et al, 2005).

Bumbu segar giling biasanya banyak ditemukan di pasar tradisional (Mujianto et al, 2013). Di Kota Padang terdapat beberapa pasar tradisional yang menjual bumbu-bumbu giling seperti bawang merah giling, bawang putih giling, jahe giling dan lengkuas giling. Bumbu-bumbu ini biasanya digiling sendiri oleh penjualnya dalam jumlah yang sangat banyak untuk persediaan beberapa hari. Agar bumbu tahan beberapa hari biasanya ditambahkan garam yang berfungsi sebagai pengawet alami. Tetapi jika garam yang ditambahkan terlalu banyak, tentu saja akan merugikan konsumen karena konsumsi garam tinggi menyebabkan hipertensi, penyakit jantung, pengeroposan tulang, peningkatan sekresi air empedu sehingga menimbulkan gangguan ginjal. Oleh karena itu perlu dilakukan penelitian yang tujuannya untuk mengetahui konsentrasi garam yang ditambahkan pada jahe dan lengkuas giling di beberapa pasar tradisional di kota Padang.

\section{METODOLOGI PENELITIAN}

\section{A. Tempat dan Waktu Penelitian}

Penelitian ini telah dilaksanakan di Laboratorium Program Studi Teknologi Hasil Pertanian Fakultas Teknologi Pertanian Universitas Andalas pada bulan Juli hingga September 2016. 


\section{B. Bahan dan Peralatan}

Bahan yang digunakan pada penelitian ini adalah bumbu jahe giling dan lengkuas giling yang diambil dari beberapa pasar tradisional di Kota Padang. Bahan yang digunakan untuk analisis antara lain aquadest, $\mathrm{AgNO} 30,1 \mathrm{M}, \mathrm{K} 2 \mathrm{CrO} 4,5 \%$, indicator universal.

Alat-alat yang digunakan dalam penelitian ini antara lain : oven, cawan aluminium, desikator, tangrus, cawan porselen, buret, corong pemisah, beaker glass, erlenmeyer, kertas saring whatman, batang pengaduk, labu Erlenmeyer, labu terukur, neraca kasar, neraca analitik, oven, pipet volume, pipet tetes, corong kecil, gelas ukur.

\section{Prosedur Penelitian}

Sampel diambil di beberapa pasar tradisional terutama yang dikelola oleh Pemerintah Daerah diantaranya Pasar Bandar Buat, Pasar Lubuk Buaya, Pasar Belimbing, Pasar Bandar Buat dan Pasar Raya Padang. Pengambilan sampel menggunakan metode Purposive Sampling dengan mempertimbangkan bahwa jahe giling dan lengkuas giling berasal dari penyalur atau pedagang yang memproduksi sendiri, diambil dari pedagang yang paling ramai dikunjungi dan paling banyak menjual jahe giling dan lengkuas giling, dimana masing-masing diwakili oleh dua pedagang. Kemudian masingmasing sampel diambil sebanyak 100 gr dan dimasukkan ke dalam plastik setelah itu dilakukan pemeriksaan di laboratorium. Pengambilan sampel dilakukan pada pagi hari (sekitar pukul 08.00 WIB), serta analisa sampel dilakukan secara duplo. Analisis keamanan jahe giling dan lengkuas giling yaitu berupa pengujian konsentrasi garam $(\mathrm{NaCl})$ yang terkandung pada bumbu-bumbu giling tersebut.

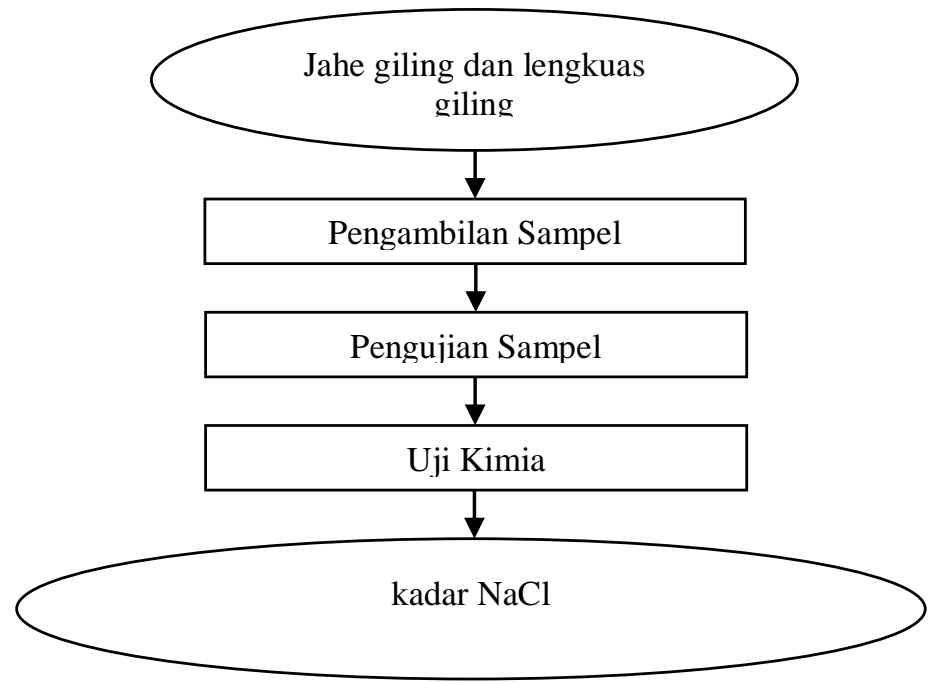

Gambar 1. Bagan Alir Penelitian

\section{Analisis Kadar Garam (NaCl) Metode Mohr}

Prinsipnya sampel kering hasil pengabuan dapat langsung dititrasi dengan perak nitrat. Ion-ion perak mengendap sebagai perak klorida sampai ion klorida habis dan kelebihan perak diukur dengan potassium kromat. Cara kerjanya adalah sebagai berikut : sampel ditimbang sebanyak $5 \mathrm{~g}$ dan diabukan seperti pada cara penetapan kadar abu. Abu dicuci dengan aquadest sedikit mungkin dan dipindahkan ke dalam erlenmeyer $250 \mathrm{ml}$. kemudian ditambahkan $1 \mathrm{ml}$ larutan kalium kromat 5\% dan titrasi dengan larutan perak nitrat $0,1 \mathrm{M}$. titik akhir titrasi tercapai apabila timbul warna merah keruh yang pertama. Kandungan garam dapat dihitung dengan rumus:

$\%$ garam $(\mathrm{NaCl})=\frac{T \times M \times 5,84}{W}$

dengan:

$$
\begin{aligned}
& \mathrm{T}=\text { titer } \\
& \mathrm{M}=\text { molaritas perak nitrat } \\
& \mathrm{W}=\text { berat sampel }
\end{aligned}
$$




\section{HASIL DAN PEMBAHASAN}

Metode Mohr merupakan salah satu bentuk metode Titrasi Argentometri, yaitu metode titrasi untuk menentukan kadar zat dalam suatu larutan yang dilakukan dengan pembentukan endapan bersama ion $\mathrm{Ag}^{+}$. Prinsip kerja penentuan konsentrasi $\mathrm{NaCl}$ dengan menggunakan metode Mohr adalah mentitrasi ion klorida yang terdapat pada $\mathrm{NaCl}$ dengan menggunakan larutan $\mathrm{AgNO}_{3}$ dengan menggunakan $\mathrm{K}_{2} \mathrm{CrO}_{4}$ sebagai indikator (Agung, 2009).

Menurut Underwood dan Day (1992), Larutan $\mathrm{AgNO}_{3}$ dan larutan $\mathrm{NaCl}$ pada awalnya masingmasing merupakan larutan yang jernih dan tidak berwarna. Ketika $\mathrm{NaCl}$ ditambahkan dengan aquades larutan tetap jernih dan tidak berwarna dan aquades tersebut larut dalam larutan. Penambahan aquades ini dimaksudkan agar $\mathrm{pH}$ larutan tidak terlalu asam ataupun terlalu basa. Setelah ditambahkan indikator $\mathrm{K}_{2} \mathrm{CrO}_{4}$, larutan kemudian berubah warna menjadi kuning mengikuti warna $\mathrm{K}_{2} \mathrm{CrO}_{4}$ yang ditambahkan. Setelah dititrasi dengan $\mathrm{AgNO}_{3}$, awalnya terbentuk endapan berwarna putih yang merupakan $\mathrm{AgCl}$. Ketika $\mathrm{NaCl}$ sudah habis bereaksi dengan $\mathrm{AgNO}_{3}$, sementara jumlah $\mathrm{AgNO}_{3}$ masih ada, maka $\mathrm{AgNO}_{3}$ kemudian bereaksi dengan indikator $\mathrm{K}_{2} \mathrm{CrO}_{4}$ membentuk endapan $\mathrm{Ag}_{2} \mathrm{CrO}_{4}$ yang berwarna merah keruh. Endapan tersebut adalah endapan $\mathrm{AgCl}$. Setelah semua ion $\mathrm{Cl}^{-}$mengendap dengan sempurna, kelebihan 1-2 tetes larutan $\mathrm{AgNO}_{3}$ akan bereaksi dengan ion kromat membentuk endapan perak kromat yang berwarna merah. Reaksi yang terjadi dapat digambarkan sebagai berikut:

$$
\begin{aligned}
& \mathrm{Ag}^{+}+\mathrm{Cl}^{-} \longrightarrow \mathrm{AgCl} \text { (putih) } \\
& 2 \mathrm{Ag}^{+}+\mathrm{CrO}_{4}^{2-} \longrightarrow \mathrm{Ag}_{2} \mathrm{CrO}_{4} \text { (merah keruh) }
\end{aligned}
$$

Untuk dapat melakukan titrasi dengan baik, maka ada beberapa hal yang harus diperhatikan yaitu $\mathrm{pH}$ larutan, dimana $\mathrm{pH}$ larutan harus dalam suasana netral atau basa lemah $(\mathrm{pH}=6-8)$. Hal tersebut harus dilakukan karena jika berlangsung dalam suasana asam, maka konsentrasi ion $\mathrm{CrO}_{4}{ }^{2-}$ akan berkurang. Kemudian jika titrasi dilakukan dalam suasana basa kuat, maka akan timbul suatu endapan peroksida. Selain itu, titrasi juga harus dilakukan secara cepat dan pengocokan harus dilakukan dengan kuat agar $\mathrm{Ag}^{+}$tidak teroksidasi menjadi $\mathrm{AgO}$ yang akan menyebabkan titik akhir titrasi menjadi sulit tercapai.

Indikator menyebabkan terjadinya reaksi pada titik akhir dengan titran sehingga terbentuk endapan yang berwarna merah bata yang menunjukkan titik akhir karena warnanya berbeda dengan warna endapan analat dengan $\mathrm{Ag}^{+}$. Pada analisis $\mathrm{Cl}^{-}$mula-mula terjadi reaksi:

$$
\mathrm{Ag}^{+}(a q)+\mathrm{Cl}_{(a q)}^{-} \longrightarrow \mathrm{AgCl}_{(s)}
$$

Sedangkan pada titik akhir, titran juga bereaksi menurut reaksi berikut :

$$
2 \mathrm{Ag}^{+}(a q)+\mathrm{CrO}_{4}{ }^{2-}(a q) \longrightarrow \mathrm{Ag}_{2} \mathrm{CrO}_{4}(s)
$$

Menurut Harjadi (1993), Selama titrasi mohr larutan harus diaduk dengan baik karena jika tidak maka secara lokal terjadi kelebihan titran yang menyebabkan indikator mengendap sebelum titik ekivalen tercapai dan dioklusi oleh endapan $\mathrm{AgCl}$ yang terbentuk kemudian sehingga titik akhir menjadi tidak sharp.

Natrium Klorida (NaCL) atau yang biasa dikenal dengan sebutan garam dapur sudah sejak lama dikenal masyarakat sebagai pemberi rasa asin dan dapat mencegah kebusukan. Garam termasuk bahan pengawet GRAS (Generally Recognize as Safe) sehingga aman dan tidak berefek toksik. Kemampuan garam sebagai pengawet disebabkan mampu berperan sebagai penghambat selektif mikrooorganisme pencemar tertentu dan garam mampu mempengaruhi water activity suatu substrat sehingga mengontrol pertumbuhan mikroba. Hasil analisa kadar garam Jahe Giling dan Lengkuas Giling di Beberapa Pasar di Kota Padang disajikan dalam tabel berikut. 
Tabel 1. Kadar Garam Jahe Giling di Beberapa Pasar di Kota Padang

\begin{tabular}{ccc}
\hline No & Pasar / Kode & Rata-rata Kadar Garam Jahe Giling (\%) \\
\hline 1 & BD & 0,7355 \\
2 & BL & 1,1534 \\
3 & LB & 0,7143 \\
4 & PR & 0,6547 \\
5 & ST & 0,8996 \\
\hline
\end{tabular}

Tabel 2. Kadar Garam Lengkuas Giling di Beberapa Pasar di Kota Padang

\begin{tabular}{ccc}
\hline No & Pasar / Kode & Rata-rata Kadar Garam Lengkuas Giling (\%) \\
\hline 1 & BD & 0,6584 \\
2 & BL & 0,8955 \\
3 & LB & 0,9663 \\
4 & PR & 0,6710 \\
5 & ST & 0,8375 \\
\hline
\end{tabular}

Berdasarkan tabel diatas dapat dilihat bahwa konsentrasi garam (Natrium Klorida) yang ditambahkan pada jahe giling dan lengkuas giling di beberapa Pasar Tradisional di Kota Padang berkisar antara 0,6547 - 1,1534\% untuk Jahe giling dan 0,6584 - 0,9663\% untuk Lengkuas giling. Ini artinya hanya sekitar $655 \mathrm{mg}-1.154 \mathrm{mg} / 100 \mathrm{gr}$ jahe giling dan $658 \mathrm{mg}-966 \mathrm{mg} / 100$ lengkuas giling. Bervariasinya kadar garam yang ditambahkan pada jahe dan lengkuas giling dibeberapa pasar di kota Padang ini disebabkan karena perbedaan kadar penambahan garam yang dilakukan oleh pedagang. Hal ini disebabkan karena tidak adanya takaran yang pasti atau standar baku sehingga konsentrasi garam yang ditambahkan tidak terukur dengan jelas. Rosaria (2007) dalam penelitiannya menyatakan bahwa pedagang umumnya menambahkan garam dalam takaran sendok makan bahkan tak jarang beberapa dari mereka menambahkan garam dengan tangan. Tetapi sekitar $30 \%$ pedagang mengetahui penambahan garam yang mereka lakukan karena mereka menggunakan garam dalam kemasan ukuran tertentu sehingga jumlah garam yang ditambahkan dapat dinyatakan dalam jumlah yang jelas yaitu sekitar 0,5-10\%.

Menurut Yenrina (2014), penambahan garam yang dilakukan oleh pedagang bertujuan untuk memperlambat kerusakan bumbu giling yang dijual tetapi juga diusahakan tidak menimbulkan rasa yang terlalu asin. Pada tabel dapat dilihat bahwa konsentrasi garam yang ditambahkan oleh pedagang jahe dan lengkuas giling dibeberapa pasar tradisional di kota Padang ini kurang dari $2 \%$. Menurut Soekarto (1985), penambahan garam dengan konsentrasi 1-2\% bertujuan untuk memberikan rasa asin pada bahan makanan yang ditambahkan, sedangkan untuk pengawetan ditambahkan garam dengan konsentrasi 5-15\%. Hal ini memperlihatkan bahwa penambahan garam (Natrium Klorida) yang dilakukan oleh pedagang bumbu giling di beberapa pasar tradisional di kota padang hanya sebagai pemberi rasa asin pada masakan bukan sebagai pengawet bumbu giling tersebut karena konsentasi garam yang ditambahkan kurang dari 5\%, dimana konsentrasi garam $(\mathrm{NaCl})$ tertinggi terdapat pada jehe giling yaitu hanya sekitar 1,15\%. Dalam penelitiannya, Rosaria (2007) menyatakan bahwa garam yang ditambahkan oleh pedagang selain bertujuan memberikan rasa asin juga mampu mengurangi kelarutan oksigen dan mempengaruhi Aw suatu bahan pangan.

Selain untuk memberikan rasa asin pada jahe dan lengkuas giling, penambahan garam juga bertujuan untuk mempermudah proses penggilingan. Garam yang digunakan umumnya adalah garam kasar karena selain memudahkan proses penggilingan, harganya juga lebih ekonomis jika dibandingkan dengan garam halus (garam meja). Menurut Nasoetion dan Karyadi (1988), garam kasar dibuat tanpa proses pemurnian (refining) yang baik dan umumnya dilakukan secara sederhana sehingga seringkali terdapat kontaminasi fisik seperti pasir, kotoran plastik dan bebatuan kecil. Hal ini dapat berdampak pada kualitas jahe dan lengkuas giling karena garam yang digunakan memiliki kualitas rendah. 
Selain garam, untuk mempermudah penggilingan juga ditambahkan air sehingga diperoleh jahe dan lengkuas giling yang tidak terlalu bulky dan memiliki rendemen yang lebih banyak sehingga menguntungkan pedagang. Sama halnya dengan penambahan garam, umumnya jumlah air yang ditambahkan pedagang juga tidak memiliki takaran yang pasti sehingga terdapat perbedaan kehalusan gilingan jahe dan lengkuas pada setiap pedagang disetiap pasar tradisional di kota Padang.

Menurut Muchtadi (1993), Dalam tubuh garam yang dikonsumsi sebagian besar akan diserap oleh usus dan dibuang kembali oleh ginjal melalui urin. Akan tetapi bila jumlah yang dikonsumsi melebihi kapasitas, ginjal untuk mengeluarkannya kembali sehingga kadar natrium dalam darah akan meningkat. Untuk mengembalikan kadar natrium darah ke tingkat yang normal, tubuh mengaturnya dengan cara menambah jumlah cairan dalam darah untuk mengencerkan kelebihan natrium tersebut. Akibatnya volume darah yang bersirkulasi dalam sistem sirkulasi bertambah jumlahnya, dan apabila jumlah ini melebihi volume tertentu, maka tekanan di dalam sistem tersebut meningkat, dan orang yang mengalaminya dikatakan menderita penyakit darah tinggi (essential hypertension).

Tubuh membutuhkan kurang dari tujuh gram garam dapur sehari atau setara dengan $3.000 \mathrm{mg}$ natrium. Kebanyakan makanan yang kita konsumsi sehari-hari kandungan garamnya lebih banyak dari kebutuhan tubuh per hari. Selain meningkatkan tekanan darah, kadar garam yang tinggi dalam tubuh juga membuat kerja ginjal jadi jauh lebih berat. Satu sendok teh garam dapur berisi $2.000 \mathrm{mg}$ natrium. Natrium yang terkandung dalam setiap menu modern rata-rata sekitar $500 \mathrm{mg}$. Pada takaran itu, ginjal perlu bekerja lebih keras untuk tetap mempertahankan keseimbangan cairan dan asam-basa tubuh agar tidak muncul penyakit akibat kelebihan natrium (Lawalangy, 2007). Konsumsi garam yang rendah juga dapat menyebabkan volume darah menurun sehingga tekanan darah ikut turun, denyut jantung meningkat, pusing, kadang-kadang disertai kram otot, lemas, lelah, kehilangan selera makan, daya ingat menurun, daya tahan terhadap infeksi rendah, luka sulit untuk disembuhkan, gangguan penglihatan, rambut tidak sehat dan bercabang ujungnya serta terbentuknya bercak-bercak putih di kuku.

\section{KESIMPULAAN}

Kadar Natrium Klorida $(\mathrm{NaCl})$ yang teridentifikasi pada sampel jahe giling dan lengkuas giling di beberapa pasar tradisional di kota Padang kurang dari 2\%. Penambahan Natrium Klorida $(\mathrm{NaCl})$ bertujuan sebagai pemberi rasa asin pada bahan makanan bukan sebagai bahan pengawet.

\section{DAFTAR PUSTAKA}

Agung, T.U. 2009. Analisis Kadar Klorida pada Air dan Air Limbah dengan Metode Argentometri (KTI) [Skripsi]. Medan : Universitas Sumatera Utara.

Hambali, Erliza., A. Suryani dan M. Rivai. 2005. Membuat Aneka Bumbu Instan Pasta. Jakarta : Penebar Swadaya.

Harjadi, W. 1993. Ilmu Kimia Analitik Dasar. Jakarta : Universitas Indonesia Press.

Lawalangi.2007. Awas Aneka Penyakit Akibat Garam. https://lawalangy.wordpress.com/2007/06/22/awas-aneka-penyakit-akibat-garamdapur/[22 September 2016].

Muchtadi, D., M. Astawan, dan N.S. Palupi. 1993. Metabolisme Zat Gizi, Sumber, Fungsi dan Kebutuhan bagi Manusia. Jakarta: Pustaka Sinar Harapan.

Mujianto, B., Angki P., Siti R. 2013. Identifikasi Pengawet dan Pewarna Berbahaya Pada Bumbu Giling. Jurnal Ilmu \& Teknologi Kesehatan. Jilid 1: hlm 34-39. Nomor 1.

Nasoetion, A.H. dan D. Karyadi. 1988. Pengetahuan Gizi dan Mineral. Jakarta : PT. Gramedia.

Rosaria. 2007. Studi Keamanan Cabe Giling di Kota Bogor [Skripsi]. Bogor : IPB.

Soekarto, S. 1985. Penilaian Organoleptik untuk Industri Pangan dan Hasil Pertanian. Jakarta : Bhratara Karya Aksara.

Underwood, A.L dan Day, R.A. 1992. Analisa Kimia Kuantitatif (Edisi Kelima). Jakarta : Erlangga. Yenrina, Rina dkk. 2014. Studi Keamanan dan Daya Simpan Kunyit Giing yang dijual dibeberapa Pasar Tradisonal di Kota Padang. Prosiding Seminar Nasional. ISBN 978-979-98691-6-. 